amplio reconocimiento para luego pasar al olvido. En la década de 1930, vuelve a convertirse en un tema de interés como problema sanitario y en la de 1950 resurge como objeto de estudio sistemático en tanto cardiopatía específica. Este devenir entre descubrimiento, opacidad, reconocimiento e invisibilidad, muestra al Chagas como parte integral de eventos biológicos de larga duración que se han transformado en hechos políticos.

En este sentido, podemos advertir que el estudio de las epidemias como mosaicos de conocimientos y poder, revelan más las características sociales, culturales y políticas de configuraciones construidas con elementos ya existentes en el mundo social, que las derivadas de factores biológicos o médicos. Son cajas de resonancia de las variaciones de lo social, cuya melodía, un investigador atento siempre está dispuesto a escuchar a fin de hacer comprensible la totalidad del problema desde diversos puntos de vista. Esto incluye las tensiones y contradicciones de las experiencias locales evidenciadas tanto en el campo médico y científico, como en el lego, en las políticas sanitarias y en las formas de recibirlas e interpretarlas por parte de los sujetos en el mundo de su vida cotidiana.

\section{REFERENCIAS BIBLIOGRÁFICAS}

1. Zabala JP. La enfermedad en su laberinto: avances, desafíos y paradojas de cien años del Chagas en Argentina. Salud Colectiva. 2012;8(Supl 1):S9-S21.

2. Downey GL, Dumit J, editors. Cyborgs and Citadels: Anthropological interventions in emerging sciences and technologies. New Mexico: School of American Research Press; 1997.

3. Fassin D. When bodies remember: Experiences and politics of AIDS in South Africa. Berkeley: University of California Press; 2007.

4. Fabian J. Time and the other: How Anthropology makes its object. New York: Columbia University Press; 1983.

\section{FORMA DE CITAR}

Stagnaro AA. Resonancias sociales y políticas del estudio social de una enfermedad. [Debate]. Salud Colectiva. 2012;8 (Supl 1):S25-S27.

\title{
Comentarios acerca de "La enfermedad en su laberinto: avances, desafíos y paradojas de cien años del Chagas en Argentina"
}

\section{Comments on "The disease in its labyrinth: advances, challenges and paradoxes over 100 years of Chagas in Argentina"}

\author{
Freilij, Héctor $^{1}$ \\ ${ }^{1}$ Médico. Consultor, Servicio de Parasitología y Chagas, \\ Hospital de Niños Dr. Ricardo Gutierrez. Responsable médico \\ del Programa Nacional de Chagas, Ministerio de Salud de la \\ Nación, Argentina. hectorfreilij@yahoo.com.ar
}

Comentario sobre: Zabala JP. La enfermedad en su laberinto: avances, desafíos y paradojas de cien años del Chagas en Argentina. Salud Colectiva. 2012;8(Supl 1):S9-S21.

El trabajo del Doctor Juan Pablo Zabala (1) muestra un profundo conocimiento de las dificultades que surgen en la lucha contra la principal endemia parasitaria de nuestro país. Pone en evidencia las diferentes causalidades, actores $y$ detractores para llevar a cabo una exitosa tarea. También es muy interesante la reseña histórica de lo que aconteció en nuestro país.

Desearía destacar un párrafo que dice "la enfermedad de Chagas no ha sido tan olvidada como para desaparecer de la agenda, ni tan recordada como para cortar definitivamente su ciclo de reproducción" (1 p.10). Este concepto explica claramente el porqué de la postergación de los buenos resultados: la discontinuidad de las tareas.

Dentro de los actores responsables de este "fracaso" menciona dos grandes cuerpos: a) los aspectos científicos y tecnocráticos y b) lo político-comercial.

Respecto al primero, menciona la falta de una vacuna. Cabe señalar que hasta el día de hoy se han desarrollado vacunas para virus, bacterias, toxinas pero no se han podido lograr para los parásitos, lo cual se debe, entre otros motivos, a la gran complejidad biológica que tienen los protozoarios. Ejemplo de esto es la imposibilidad de contar con una vacuna para un protozoario de 
mucho mayor impacto en la salud como es el Plasmodium, responsable de la malaria.

Respecto a los aspectos políticocomerciales podemos señalar que, desde los años 1950 en los que se iniciaron las acciones de lucha contra esta endemia, el interés de los gobiernos ha sido desigual. Otra dificultad es producto de ser un país federal: cada provincia decide, organiza y ejecuta sus propias medidas de salud; y no todas las provincias han mostrado tener un interés similar para llevar a cabo acciones en esta dirección. Es más, en algunas provincias, muchos de los avances surgen del fuerte interés de algunos jefes de los programas provinciales que con ahínco luchan denodadamente para que se ejecuten las tareas.

En otro párrafo el autor dice "el Chagas es una entidad compleja, condicionada tanto por los procesos biológicos involucrados como por los intereses profesionales, económicos, políticos, culturales e institucionales" (1 p.10). Esta es una sentencia común a casi todas las enfermedades. No obstante, es importante recalcar que varios países han logrado la interrupción de la transmisión vectorial domiciliaria. Esto significa que si el interés y el compromiso existen, los logros son posibles, incluso con los baches de los conocimientos actuales.

Dentro de las paradojas a que hace mención el autor, deseo hacer algunas reflexiones sobre los aspectos biomédicos, por ejemplo, la dicotomía infectado-enfermo. Es común que se diga que no debemos asustar a una persona que tiene una serología reactiva con un electrocardiograma (ECG) y radiografía de tórax normales, poniéndole el rótulo de enfermo. Esto encierra un grave error: toda persona que desarrolla una morbilidad grave e incluso muere por esta infección, en algún momento pasó por un estadio asintomático. Algo similar sucede con un paciente hipertenso, puede tener la presión arterial elevada y no tener síntomas, pero en algún momento puede desarroIlar severas enfermedades. A una persona que tiene presión alta asintomática ¿acaso no le decimos enfermo? Además, si se realizaran procedimientos diagnósticos cardiológicos de mayor sensibilidad en pacientes con Chagas, se podrían detectar alteraciones cardíacas en individuos que tienen un ECG normal. Esto generó la actual redefinición de paciente de fase crónica: a) con patología demostrada o b) sin patología demostrada (2).

Es muy buena la descripción de las vicisitudes que sufrió la enfermedad a partir de que Carlos Chagas le atribuyó al Trypanosoma cruzi la responsabilidad del bocio, lo que demuestra que este brillante investigador es un ser humano, pasible de cometer errores de interpretación.

Dentro de los actores responsables de las diferentes acciones, un capítulo a mencionar son los médicos que, en general, no desean ocuparse de esta enfermedad, para lo cual hay varias explicaciones posibles: a) desconocen la enfermedad de Chagas y su historia natural en los individuos infectados, b) desconocen los beneficios de instalar un tratamiento parasitici$\mathrm{da}, \mathrm{c})$ temen a los efectos adversos que pueden producir las únicas dos drogas con las que se cuenta desde los años 1970, d) no tienen la presión de la industria farmacéutica. Este conjunto de situaciones conlleva el escaso interés por ocuparse de estos pacientes, amén de que no les produce beneficios económicos. Todo esto es solucionable, en parte, con sostenidas acciones de capacitación.

Respecto a otro párrafo referente a las "enfermedades olvidadas" es conveniente mencionar que no solo sucede en Latinoamérica, África y Asia sino en EE.UU. donde los pacientes con esta parasitosis no reciben la atención debida.

Se señala que hay varios tipos de dificultades para llevar a cabo una adecuada lucha vectorial en áreas como el Gran Chaco, debido a las características climáticas, habitacionales, fitogeográficas, etc. Pero deseo mencionar que acaban de ser certificados en cuatro departamentos de la provincia de Santiago del Estero, en pleno corazón del Gran Chaco, la interrupción de la transmisión vectorial domiciliaria (3). Esto nos dice a las claras que si existe la decisión política, la acción se ejecuta a pesar de todas las adversidades.

Son adecuadas las reflexiones sobre la importancia de la investigación en el avance de esta lucha, que en mayor medida favoreció al mejoramiento de los diagnósticos y a algunos aspectos entomológicos (resistencia a insecticidas, concentraciones del uso de los insecticidas). 
Respecto a la medicación podemos decir que, si bien no hay hasta el momento un fármaco nuevo, podemos contar con los dos tradicionales: el benznidazol (producido por una empresa nacional) y el nifurtimox (el laboratorio la vuelve a producir). Además se están realizando ensayos en humanos con medicamentos para el tratamiento de hongos que han resultado eficaces para el Trypanosoma cruzi, en los modelos animales.

Por último deseo mencionar a la ONG internacional Drugs for Neglected Diseases Initiative (DNDi), que se ocupa intensamente de conseguir mayor acceso a los medicamentos a nivel internacional, y a Médicos sin Fronteras con una vasta experiencia en diagnóstico y tratamiento en diversos países de América. Otras dos fundaciones nacionales con activa participación para esta enfermedad son Mundo Sano y Bunge y Born. Quiero señalar, además, que la enfermedad de Chagas tiene un gran cambio epidemiológico: está urbanizada por migraciones desde áreas endémicas. Gran cantidad de niños y adultos infectados viven en ciudades grandes y pequeñas de diferentes partes del mundo. En Argentina, debemos impulsar la atención de los pacientes en los tres sistemas de atención: el público, las obras sociales y el privado. En todos ellos hay pacientes con Chagas.

Con idas y vueltas, las acciones tanto vectoriales como no vectoriales van progresando en nuestro país y los números son alentadores. Se hizo mucho, pero mucho es aún lo que resta por hacer.

\section{REFERENCIAS BIBLIOGRÁFICAS}

1. Zabala JP. La enfermedad en su laberinto: avances, desafíos y paradojas de cien años del Chagas en Argentina. Salud Colectiva. 2012;8(Supl 1):S9-S21.

2. Federación Argentina de Cardiología. Clasificación Enfermedad de Chagas: Consenso Internacional Buenos Aires 2010 [Internet]. 20 mar 2010 [citado 8 oct 2012]. Disponible en: http://www.fac.org.ar/1/revista/11v40n3/ consenso/chagas/mordini.php.

3. Un corte al mal de Chagas. Página/12 [Internet]. 30 ago 2012 [citado 8 oct 2012]. Disponible en: http://www.pagina12.com.ar/diario/sociedad/3202218-2012-08-30.html.

\section{FORMA DE CITAR}

Freilij H. Comentarios acerca de "La enfermedad en su laberinto: avances, desafíos y paradojas de cien años del Chagas en Argentina". [Debate]. Salud Colectiva. 2012;8(Supl 1):S27-S29.

\section{Comentario sobre el criterio de visibilidad e invisibilidad en la enfermedad de Chagas-Mazza}

\section{Commentary on the criterion of visibility and invisibility in Chagas- Mazza disease}

\author{
Auger, Sergio ${ }^{1}$ \\ ${ }^{1}$ Médico, Especialista en Cardiología. Jefe de Departamento de \\ Consultorios Externos, Coordinador del Comité Integral de \\ Chagas, Hospital General de Agudos Donación Francisco \\ Santojanni, Argentina. Referente hospitalario, Red de Chagas \\ del Gobierno de la Ciudad de Buenos Aires. Secretario \\ Científico, Consejo de Chagas, Sociedad Argentina de \\ Cardiología.sergioauger@aol.com
}

Comentario sobre: Zabala JP. La enfermedad en su laberinto: avances, desafíos y paradojas de cien años del Chagas en Argentina. Salud Colectiva. 2012;8(Supl 1):S9-S21.
El artículo de Juan Pablo Zabala (1) pone en evidencia las paradojas de la enfermedad de Chagas desde su descubrimiento y lo hace desde una visión de "visibilidad e invisibilidad de la enfermedad". Lamentablemente, la visibilidad de la enfermedad se hace presente, en general, cuando se acercan los actos eleccionarios para gobernadores, intendentes o presidentes de un país. La promesa, para esta población en situación de pobreza, es la construcción de una vivienda digna, la fumigación con periodicidad, una mejor nutrición y el suministro de luz eléctrica y agua. Sin embargo, una vez realizadas las elecciones, estas promesas no llegan. Otros que sí la tienen presente son los investigadores de campo y quienes se dedican a la atención cotidiana y al seguimiento de estos pacientes en las grandes urbes.

La invisibilidad es creada por la sociedad, que generalmente desconoce que existen personas con esta enfermedad porque creen que solo es de pobres y jamás piensan que pueden 